\title{
O PAPEL DO VOLUNTARIADO NA EMANCIPAÇÃO EM DIREITOS HUMANOS DE COMUNIDADES VULNERÁVEIS
}

\author{
THE ROLE OF VOLUNTEERING IN THE HUMAN RIGHTS EMANCIPATION \\ OF VULNERABLE COMMUNITIES
}

Cláudio Renan Corrêa Filho ${ }^{1}$

\begin{abstract}
Resumo: O artigo busca analisar a importância da participação de ações de voluntariado junto a comunidades vulneráveis para sua emancipação democrática em uma cultura de direitos humanos. O problema que orienta a pesquisa pode ser sintetizado na seguinte pergunta: Em que medida as ações de voluntariado podem contribuir na emancipação democrática de comunidades vulneráveis, auxiliando na criação de uma cultura proativa de direitos humanos? O objetivo geral consistiu em analisar como as organizações sociais de trabalho voluntário podem contribuir para a criação de uma cultura de direitos humanos em comunidades vulneráveis. Especificamente, procuramos: a) apresentar a questão dos direitos humanos enquanto um contexto de lutas; b) estudar a atuação das organizações sociais de trabalho voluntário e sua importância na sociedade atual; c) investigar a importância da atuação dessas organizações sociais junto às comunidades vulneráveis para a criação de uma cultura de direitos humanos. O método de pesquisa empregado foi o hipotético-dedutivo, mediante o emprego de pesquisa bibliográfica. Com base nos dados levantados e pesquisas realizadas na área do Direito e Ciências Sociais correlatas, refletidos na bibliografia que sustenta o estudo, é possível afirmar que o voluntariado pode e deve contribuir junto às comunidades vulneráveis em uma criação de cultura ativa de direitos humanos.
\end{abstract}

Palavras-chave: Direitos Humanos, Voluntariado, Emancipação Democrática.

\begin{abstract}
This article seeks to analyze the importance of volunteer work in vulnerable communities for their democratic emancipation in a human rights culture. The problem that guides this research can be summarized in the following question: To what extent can volunteer work contribute to the democratic emancipation of vulnerable communities, helping to create a proactive human rights culture? The general objective was to analyze how social volunteer work organizations can contribute to the creation of a human rights culture in vulnerable communities. Specifically, we sought: a) to present the issue of human rights as a context of struggles; b) to study the performance of social volunteer work organizations and their importance in today's society; c) to investigate the importance of the performance of these social organizations in vulnerable communities for the creation of a human rights culture. The research method used was the hypothetical-deductive one, through the use of bibliographical research. Based on the data gathered and the research carried out in the area of Law and related Social Sciences, reflected in the bibliography that sustains the study, it is possible to affirm that volunteer work can and should contribute to the creation of an active culture of human rights in vulnerable communities.
\end{abstract}

Keywords: Human Rights, Volunteering, Democratic Emancipation.

\footnotetext{
${ }^{1}$ Mestrando do Programa de Pós- Graduação em Direitos Humanos da Universidade Regional do Noroeste do Rio Grande do Sul - UNIJUÍ, na linha de pesquisa "Democracia, direitos humanos e desenvolvimento"; Membro do grupo de pesquisa "Direitos Humanos, Governança e Democracia", da Universidade Regional do Noroeste do Estado do Rio Grande do Sul; Graduado em Ciências Jurídicas e Sociais pela Universidade Federal de Santa Maria - UFSM; Servidor Público da Justiça Federal em Santa Maria/RS. ORCID Id: https://orcid.org/0000-0001-71857886. Lattes: http://lattes.cnpq.br/9765972673407611. E-mail: claudiocorrea@ gmail.com.
} 


\section{Considerações iniciais}

Este artigo pretende analisar a importância da participação das organizações sociais de trabalho voluntário junto a comunidades vulneráveis, com o escopo de uma emancipação democrática em uma cultura de direitos humanos. Tal tema ganha grande relevância atualmente, pois são inúmeros os desafios carreados pelo Estado democrático, atingindo de forma mais direta os vulneráveis, que veem seus já parcos direitos sendo restringidos pelas necessidades do modelo neoliberal. Assim, as ações voluntárias podem colaborar em uma criação de cultura de lutas pelos direitos humanos, especialmente para a população que está à margem desse sistema.

O problema que orienta as investigações aqui declinadas é delinear em que medida as ações de voluntariado podem contribuir na emancipação democrática em comunidades vulneráveis, auxiliando na criação ou fomento de uma cultura proativa de direitos humanos?

Em uma hipótese inicial, considerando as pesquisas realizadas sobre o tema na área do Direito e Ciências Sociais correlatas, refletidas na bibliografia que sustenta o estudo, é possível afirmar que as organizações sociais de trabalho voluntário podem contribuir junto às comunidades vulneráveis em uma criação de cultura ativa de direitos humanos.

Como objetivo geral, a pesquisa busca analisar como as organizações sociais de trabalho voluntário podem contribuir para a criação de uma cultura proativa de direitos humanos. Para dar concretude ao objetivo geral, os objetivos específicos do texto, que se refletem na sua estrutura em três seções, são: a) apresentar sinteticamente a questão dos direitos humanos como um contexto de lutas; b) estudar a atuação das organizações sociais de trabalho voluntário e sua importância na sociedade atual; c) investigar a importância da atuação dessas organizações sociais junto às comunidades vulneráveis para a criação de uma cultura de direitos humanos. O método de pesquisa empregado foi o hipotético-dedutivo, mediante o emprego de pesquisa bibliográfica e documental.

\section{A questão dos direitos humanos como um contexto de lutas}

Os direitos humanos são um importante desafio do atual século, a despeito de longa data já estarem presentes no ideário popular e serem tema recorrente dos debates acadêmicos e institucionais. Desde a Declaração dos Direitos Humanos de 1948, ainda em um contexto em que o mundo ia conhecendo as atrocidades cometidas no decorrer da Segunda Guerra Mundial, os especialistas e atores internacionais vêm realizando um grande esforço para se formular uma 
base de direitos apta a alcançar todos os indivíduos e formas de vida. Ocorre que, diverso do contexto da Guerra Fria que permeava o período da confecção da Declaração de 1948, o atual momento apresenta outros desafios, especialmente as inúmeras restrições provenientes do modo de produção capitalista atual, comumente chamado de "neoliberalismo".

Em uma sociedade complexa como a que vivemos, as movimentações, sejam as de pessoas ou de capital, são direcionadas pelo máximo ganho. A estruturação desse sistema remonta aos anos de 1980, espelhando um modo de produção hipercapitalista (MORIN, 2020). Os lucros aumentam e as grandes cidades acabam por absorver somente as pessoas que possuem a especialização necessária no contexto global (SASSEN, 2010). Assim, um grande número de seres humanos vive à margem do sistema capitalista do século XXI. Ainda que tenha ocorrido uma tímida redução na desigualdade no início deste século, é certo que a dinâmica do capital segue a favorecer a acumulação dos mais abastados, uma vez que o rentismo propicia maiores ganhos que o crescimento econômico (PIKETTY, 2014).

Esse sistema ditado pelo capital que vem se tornando hegemônico acaba por normalizar as desigualdades sociais. Muitas vezes o discurso dominante justifica essa brutal disparidade com a ideia de meritocracia. Ocorre que o mérito individual nada mais é que uma herança de uma sociedade de classes. Não se pode creditar apenas ao mérito o sucesso de uma pessoa que teve as condições de se desenvolver e ao fracasso de outro ser humano apenas pela ausência de esforço, quando é sabido que muitas pessoas vivem em condições precárias, privadas de inúmeros bens necessários à uma existência digna (SOUZA, 2009). Esse discurso meritorcrático ${ }^{2}$ serve para glorificar os vencedores e estigmatizar os perdedores (PIKETTY, 2020).

A luta pela redução da desigualdade, no Brasil, sempre foi de imensa dificuldade para os atores sociais, dada a propensão das elites de manter e aumentar seus poderes. Afinal,

já é bem conhecida pelas nossas Ciências Sociais a capacidade exemplar das elites brasileiras, ao longo dos anos, de mudar para conservar. Os pactos por cima, que procuraram excluir de todas as formas o povo das decisões significativas da nação, não se configuraram como pequenos ínterins na nossa trajetória, mas se constituíram como condição sine qua non capaz de assegurar o andamento conservador da modernização no Brasil (PERLATTO, 2018, p. $55)$.

\footnotetext{
${ }^{2}$ De acordo com Chauí (2014), hoje existe uma espécie de "ideologia da competência", a qual oculta a divisão de classes originária, mas divide a sociedade entre os que possuem os conhecimentos científicos e tecnológicos ("competentes") e os que executam tarefas determinadas pelos especialistas ("incompetentes"). Alijadas do processo do capital e "não merecedoras" de uma melhor sorte, resta aos menos favorecidos o oferecimento de seu trabalho, na maior parte das vezes doméstico ou braçal, para que possa obter um mínimo financeiro para sua existência.
} 
O processo modernizador no Brasil não foi realizado da mesma forma que em outros países, uma vez que não ocorreu qualquer ruptura com o regime anterior, mas sim um contínuo entrelaçamento entre o arcaico e o moderno, constituindo uma ordem social altamente desigual (PERLATTO, 2018). No caso brasileiro, o processo de modernização que culminou com a abolição da escravidão no fim do século XIX abandonou à própria sorte toda a classe dos escravos, os quais não recuperaram qualquer função produtiva na nova ordem. Assim, formouse uma classe de párias que valem, para as elites, menos dos que os outros. Nesse contexto, não existe cidadania, mas sim cidadãos e subcidadãos (SOUZA, 2000).

Nesse estado de coisas, a simples listagem de direitos não apresenta o efeito prático ante as forças do capital, as quais tendem a prevalecer ante às populações vulneráveis, tornando sua situação ainda mais precária, uma vez que a concessão de mais direitos passa a ser visualizada pelo capitalismo como um custo. Cademartori e Grubba (2012) afirmam que se formou uma racionalidade na qual, ao separar a economia das demais instituições sociais, terminou por subordinar estas a uma ideologia puramente mercantilista. Mas, após a grande crise financeira global, o discurso neoliberal que pautou as décadas anteriores perde força, abrindo espaço para que renasça sob novos holofotes a discussão sobre os direitos humanos e toda sua complexidade. Segundo os autores, “caso não seja assim, corre-se o risco de reduzir o discurso dos direitos fundamentais à mera retórica de entrave à governabilidade, que foi hegemônica no contexto neoliberal, de uma ordem global fundada na desigualdade e exploração" (2012, p. 705).

A discussão que os direitos humanos demandam perpassa pela questão cultural. De acordo com Herrera Flores (2002), a cultura não é uma entidade alheia ou separada da ação social. É sim uma reação à forma como são constituídas as reações sociais. Por essa razão, é necessária uma visão multiculturalista emancipadora, focada na afirmação dos direitos humanos. Ainda, segundo o autor, "Torna-se relevante construir uma cultura dos direitos que recorra, em seu seio, à universalidade das garantias e ao respeito pelo diferente" (2002, p 14).

Assim, de acordo com Herrera Flores (2009), é necessária uma nova perspectiva crítica, que seja integrada em práticas sociais emancipadoras. Ao contrário do que faz entender a Declaração de 1948, os direitos humanos não são algo ínsito ao ser humano, algo que todos e todas passam a usufruir pelo simples fato de ter nascido humano. Isso decorre do fato de que, para poder desfrutar de alguns direitos, são necessários alguns bens e condições materiais que não estão disponíveis a toda a coletividade. Assim, "queremos sair desse círculo vicioso em que 
nos encerra o aparente "simplismo" da teoria tradicional que começa falando dos direitos e termina falando dos direitos" (HERRERA FLORES, 2009, p. 27).

Uma visão abstrata e localista dos direitos humanos supõe situar-se em um centro, a partir do qual se passa a interpretar todo o restante. Ocorre que, de acordo com Herrera Flores (2002), esse tipo de análise funciona como um padrão de medida e de exclusão, derivando dela um mundo desintegrado. Por essa razão, é necessário ao analista deste cenário complexo se situar na periferia, em local que não coincida com o centro, usualmente abandonado à marginalidade. Em suma,

ver o mundo a partir de um pretenso centro, supõe entender a realidade material como algo inerte, passivo, algo a que se necessita dar forma desde uma inteligência alheia a ela. Ver o mundo a partir da periferia, implica entendermo-nos como conjuntos de relações que nos atam, tanto interna como externamente, a tudo, e a todos os demais. A solidão do centro supõe a dominação e a violência. A pluralidade das periferias supõe o diálogo, a convivência (HERRERA FLORES, 2002, p. 15).

Os direitos humanos, mais que direitos, são processos, provenientes de lutas dos seres humanos para acessar os bens necessários para a vida. Segundo Ferrajoli (2002), nenhum direito fundamental do homem nasceu em uma escrivaninha ou caiu do céu. Todos foram fruto de conflitos e foram conquistados a preço de transgressões, sacrifícios e sofrimento. Assim, não se pode fazer a confusão entre os direitos positivados no âmbito nacional e internacional com o conceito da Carta de 1948, caso contrário recairíamos na falácia do positivismo. Segundo Herrera Flores (2009), o problema não é como um direito se transforma em direito humano, mas o oposto, como um direito humano consegue obter a garantia jurídica para implantação e efetividade.

De acordo com Grubba e Cadermatori (2012), ao se pressupor que direitos humanos e fundamentais são fins que devem ser perseguidos para uma vida digna, deve-se pensar em como serão fundamentados os futuros direitos que serão gerados, para que obtenham reconhecimento, legalidade e eficácia. Durante muito tempo a busca por um embasamento pautou-se na universalidade, um fundamento absoluto, metafísico e irreversível, ao qual ninguém poderia negar a adesão. Uma visão racionalista do problema torna tal visão desprovida de capacidade de mobilização geral como pretende.

Nessa toada, para Grubba (2010), a Declaração Universal de 1947, que faz de seus ideais os de todos que vivem no mundo, ao mesmo tempo aceita a noção de colonialidade e imperialismo, ao dispor de é preciso assegurar os direitos humanos inclusive nos territórios sob 
a jurisdição. É por conta dessa conjuntura que se mostra necessária a leitura da Carta de 1948 como uma proposição, um ideal a ser alcançado através de lutas sociais, pois

[...] não se trata de negar a Declaração, construída por meio de lutas sociais, mas de relativizar o alcance de suas significações, para que, por ser fruto de um processo hegemônico, não se perpetuem os espaços de castração simbólicos que impedem as pessoas de se sentirem seres humanos que necessitam buscar sua humanidade e sua noção de dignidade (GRUBBA, 2010, p. 102).

Essa nova concepção para os direitos humanos passa por uma revisão do pensamento dominante. O conhecimento difundido sempre foi representado pelo pensamento hegemônico, dominado pela epistemologia Europeia, em uma clara posição colonialista, dos ditos "países do norte" (BRAGATO, 2014; MIGNOLO, 2017). Tal epistemologia é a base na qual se pauta a Declaração Universal dos Direitos Humanos de 1948, anteriormente mencionada, a qual possui viés universalista mas, na realidade, retrata o ideário europeu ocidental e suas lutas, histórias e pretensões (BRAGATO, 2014).

Segundo Colaço e Damásio (2010), a noção de colonialidade denota uma relação na qual a soberania de um povo reside no poder de outro, ou de outra nação. Esse é um padrão de poder que surge da colonialidade moderna e tem a concepção de que o mundo não foi completamente descolonizado, uma vez que só foi dada independência política às periferias. A perspectiva descolonial deve, assim, buscar abrangência em todas as ciências, direcionada para o resgate dos saberes que foram silenciados pela colonialidade.

De acordo com Bragato (2014), a predominante fundamentação filosófica filia-se totalmente ao sistema mental da modernidade, fundamentando uma essência universal do homem. Essa essência resgata o conceito de superioridade da racionalidade, ínsito a um projeto liberal-burguês de sociedade. Assim, a principal fundamentação teórica dos direitos humanos decorre do contexto europeu moderno, o qual sugere a ausência de contribuições de fora do ocidente, colocando uma visão particular e fragmentária como se o todo fosse e representasse, focando na ideia de humanismo racional.

Dessa forma, uma cultura libertadora de direitos humanos precisa se desprender das amarras de um pensamento colonialista, com o objetivo da obtenção dos bens necessários a uma ida digna. Segundo Bragato (2014, p. 210), “O pensamento descolonial insere-se na trilha das formas de pensamento contra-hegemônicas da modernidade e inspira-se nos movimentos sociais de resistência gerados no contexto colonial". É a partir dessa contra hegemonia que deve partir o pensamento de uma cultura emancipadora de direitos humanos, focando nas 
características das comunidades e na valorização das lutas pela consecução dos valores fundamentais.

Logo, para se ter uma visão transformadora dos direitos humanos, necessário se faz a libertação das amarras ideológicas impostas pela colonialidade, aliada ao reconhecimento do contexto de lutas que permeia as relações sociais, em busca de uma visão crítica e libertadora dos fenômenos sociais. Uma ferramenta importante para essa busca pode ser representada pela atuação de organizações sociais e voluntários junto às comunidades vulneráveis.

\section{A atuação das organizações sociais junto às comunidades vulneráveis}

O atual domínio neoliberal provoca um aumento da pobreza, considerando seu espírito de acumulação e de corte de ações sociais por parte do Estado. Ao mesmo tempo, ocorre o incentivo à sociedade civil para o trabalho voluntário, fomentando o chamado "terceiro setor" a suprir as lacunas da atuação estatal. De acordo com Fagundes (2006), o uso do termo "sociedade civil" na contemporaneidade tem sido confundido com "terceiro setor", sendo identificada com organizações privadas que prestam serviços públicos, substituindo o Estado no enfrentamento da questão social. Segundo a autora, "além do Estado e do mercado, há o terceiro setor, não-governamental e não-lucrativo; entretanto ele é organizado e independente e mobiliza particularmente a dimensão voluntária do comportamento das pessoas" $(2006$, p. 7).

O terceiro setor mencionado acima é uma decorrência da organização da sociedade civil, a qual é, segundo Silva, “[...] a dimensão da sociedade na qual os cidadãos não estão dedicados de forma especial a manter e usar os mecanismos de coação e coerção com funções de controle da ordem social" (2014, p. 113). Ainda, segundo o autor,

embora imersa nos padrões instrumentais, normativos e comunicacionais, a sociedade civil possui uma comunicação mais aberta e se refere a dinâmicas socializadoras, associativas e formas de diálogos do mundo da vida nos diversos momentos de suas processualidades institucionalizantes. Ela pode exercer influências nos processos de mediação entre poderes políticos e econômicos e, ao mesmo tempo, buscar uma proteção contra a penetração destrutiva do poder político e do poder econômico. Interessa a ela, também, os valores da emancipação social, da auto-organização e autoconstituição, que preservam autonomias e formas de solidariedade (SILVA, 2014, p. 117).

Quando o Estado falha ao cumprir sua função de gerar políticas públicas, transferindo esse ônus para os particulares, surge o apelo à filantropia para o enfrentamento de determinadas questões sociais. Assim, em um contexto de valorização do setor voluntário, Estado e sociedade são, segundo Fagundes (2006), competidores no marco de uma nova “divisão do bem estar". 
Tanto isso é verdade que o próprio Estado incentiva a prática do voluntariado. Em um contexto de economia neoliberal, em que cada vez mais as ações junto aos vulneráveis são consideradas meramente como "custos", a sociedade tenta suprir as lacunas deixadas pelo poder público a fim de se propiciar um mínimo de dignidade à população carente.

A valorização do voluntariado contempla uma visão de uma "sociedade de bem-estar" ao invés de um Estado de bem-estar. Assim, vários atores são mobilizados para, em conjunto, propiciar o alívio da comunidade, sem nenhuma assunção de privilégio por parte de quaisquer desses agentes. Ainda, de acordo com Fagundes (2006), as questões da pobreza vêm sendo tratadas como questões da filantropia, avançando a um ideário de "sociedade solidária", revelando um sistema misto de proteção social, o qual contempla Estado e sociedade civil. Segundo a autora (2006, p. 13), “diante desse cenário, devemos cuidar para que a desigualdade social não seja tratada como se não houvesse implicações políticas, econômicas e culturais na sua constituição".

O voluntariado e a solidariedade devem ser identificados como importantes valores a serem resgatados, mas as políticas sociais não podem ser cooptadas por esses preceitos, uma vez que o voluntariado se dá por sentimentos subjetivos, não sendo associado a direitos e deveres. De acordo com Fagundes (2006, p. 14), “a interdependência entre setores governamentais e não-governamentais tem aumentado em vez de diminuir, o que significa a manutenção da atual configuração múltipla, que consiste em demandar a sociedade civil através das ONGs". No Brasil, ser voluntário passou a ser um passaporte para o exercício da cidadania, uma vez que é incentivado e é presente como parceiro privilegiado do Estado em todas as áreas sociais, seja através de benefícios fiscais ou pelo reconhecimento da responsabilidade social.

De acordo com Etzioni (2019), a confiança nas lideranças e instituições públicas é particularmente baixa. Em muitas sociedades há um fluxo de dinheiro privado para agentes públicos - seja por suborno ou por "contribuições" para interesses especiais. Afirma, ainda, que a corrupção nas instituições públicas é prejudicial a uma visão comunitária, uma vez que a concentração de poder viola os preceitos de uma sociedade democrática, ferindo o prisma da igualdade. Segundo Schmidt (2016), hoje existe a dúvida se apenas a vontade política é suficiente para moldar o mundo, ou se estamos submetidos a forças impessoais, macrossociais. Nesse sentido, o debate à luz da teoria comunitarista pode apresentar uma estrutura moderna de análise das políticas públicas, para além do voluntarismo racionalista e da resignação incremental. 
Diante dessa crise do Estado de bem-estar social, cresce a importância da sociedade civil como ator na consecução de direitos humanos. Em uma sociedade complexa, a antiga dicotomia público-privado não encontra mais espaço. Hoje o Estado é muito mais que poder de polícia, ao passo que os indivíduos possuem maiores deveres perante a coletividade. O indivíduo, assim, passa a ser integrante de sua sociedade. Etzioni (2019) afirma que os seres humanos aspiram a uma sociedade que não seja unicamente civil, mas boa, sendo esta a sociedade em que as pessoas tratam umas às outras como fins em si mesmas, e não como instrumentos. Os indivíduos são tratados como membros de uma comunidade, com laços de afeto e compromisso. Refere, ainda que a boa sociedade é a que equilibra Estado, mercado e comunidade, entes frequentemente referidos como incompatíveis. Assim, a boa sociedade não busca eliminar esses segmentos, mas preservá-los e contê-los. Para Schmidt (2016), uma sociedade não pode ser boa nem estável no longo prazo sem atendimento das necessidades de seus membros.

Segundo Selli e Garrafa (2006), a onipresença estatal ajuda a explicar a ênfase dada à dimensão de cidadania no Brasil. Como Estado é a referência para a questão social, e o cidadão o titular da soberania política, é tentador imaginar que o cidadão, ao assumir o controle público, possa utilizá-lo para resolver a questão social. A participação da cidadania é um sinal de maturidade política, mas não se pode imaginar que o Estado irá resolver a questão social em seus múltiplos desdobramentos. Nesse contexto surge a possibilidade de ampliação qualitativa e quantitativa do voluntariado. Não se trata, contudo, de se pensar na retirada do Estado e de suas políticas sociais, mas sim um sinergismo de esforços diante de tão complexa tarefa.

A atuação comunitária consiste em alternativa ao aparente paradoxo entre o público e o privado. Na atual crise do Estado liberal, “o Estado deixaria sua condição de provedor para assumir a função de condutor e catalisador, criando as condições para o desenvolvimento do capital social" (CERVI, 2013, p. 159). Assim, de acordo com Schmidt (2016), as comunidades assumem importância na vida humana pois suprem a necessidade de laços interpessoais, mas também pois proporcionam uma cultura moral compartilhada que pode colaborar com a ordem social. Assim,

uma boa sociedade prospera a partir de uma diversidade de culturas que enriquece a vida das pessoas através das artes, da música, da dança, do convívio social, da culinária, etc. Mas tal sociedade multicultural não pode florescer sem um marco de referência compartilhado por todos, sujeito ele mesmo à evolução. Seus elementos incluem o compromisso com um modo de vida democrático, com as normas básicas ou a Constituição, com o respeito mútuo e, acima de tudo, com a responsabilidade de tratar os outros como fins em si mesmos. A diversidade não deve se tornar o oposto da unidade, mas deve existir na unidade. (ETZIONI, 2019, p. 53) 
A partir da década de 90 ocorreu uma alteração no panorama do associativismo. Antes focado em núcleos militantes dedicados a uma causa seguindo uma organização, agora a mobilização se faz a partir do atendimento a um apelo feito por uma entidade plural, com objetivos humanitários. De acordo com Gohn (2013), o associativismo dos anos 90 passou a ser mais propositivo e menos reivindicativo, mais estratégico. O conceito básico fundamental é o da participação cidadã, na qual a categoria central deixa de ser a comunidade ou o povo e passa a ser a sociedade, aproximando o local onde ocorre a participação popular com as tomadas de decisões.

O voluntariado também é uma atividade importante para o crescimento não só das comunidades assistidas, mas também das pessoas que dedicam seu tempo a tão nobre atividade. Segundo Alcade-Corzo (2018), as contribuições do voluntariado são evidentes, além do que, em nível individual, o voluntariado é uma ferramenta educativa para desenvolvimento de capacidades e competências. Assim, a ação voluntária é precedida de uma fase formativa essencial para que a ação desencadeie uma transformação real.

Para se ter uma ideia da importância do voluntariado no desenvolvimento econômico, segundo Alcade-Corzo (2018), o voluntariado constitui o equivalente da sétima economia do mundo em produto bruto, sendo que em diversos países gera mais de $5 \%$ do produto interno bruto em bens e serviços, especialmente sociais. Cada vez mais pessoas estão envolvidas em voluntariado, sendo um fenômeno atual, o qual encontra cada vez mais formas e campos para desenvolvimento. Não à toa que diversos países criaram legislações sobre voluntariado, a exemplo da Lei $n^{\circ}$ 9.608/98 editada no Brasil.

Segundo Souza e Medeiros (2012), o voluntariado vem ganhando força aliado à promoção da cidadania. Um maior número de pessoas que se mobilizam para ajudar ao próximo e fazer algo para amenizar as mazelas socioeconômicas. Ainda que a atuação voluntária não tenha a intenção de suprir integralmente as lacunas e deficiências deixadas por uma atuação estatal restrita pelos ditames neoliberais, também há a importância de trazer um panorama positivo, descortinando um horizonte alvissareiro ou ao menos um pouco melhor do que o atual. Em pesquisa realizada junto a grupos voluntários de Madrid, Fernandez e Lopez (2007) afirmam que o ânimo dos grupos de trabalho voluntário analisados era, ainda que crítico e conhecendo as dificuldades do trabalho, claramente otimista e esperançoso. Ainda, segundo os autores (2007, p. 614), “existe una fuerte conciencia de las fallas de su acción institucional y 
piensan desde la positiva función social que realizan pero también desde esas insuficiencias que desean superar aunque en algunos aspectos no sea fácil ${ }^{3}$.

\section{0 voluntariado como ator de direitos humanos}

O voluntariado é uma atitude transformadora, tanto para o indivíduo que atua em prol de sua comunidade, como para a realidade que se desdobra a partir de suas ações. Segundo AlcadeCorzo (2018, p. 248), “Al estar en contacto directo con situaciones de injusticia y las disfunciones derivadas del sistema, se forma una conciencia social que lleva a la articulación de un discurso crítico con respecto al orden establecido y también a la denuncia social"4 . Neste sentido, segundo o autor, se acredita que existe um potencial a ser explorado entre os voluntários para uma utilização adequada de suas capacidades, que podem auxiliar na questão social.

A solidariedade que permeia a atuação das organizações da sociedade civil não deriva de doutrinas políticas ou religiosas, sendo um valor central que serve como motivador para ações que tenham como objetivo trazer benefícios às pessoas por ela atingidas. Como referido anteriormente, a expansão do neoliberalismo refletiu-se no Estado de Bem-Estar Social, apequenando a atuação do Estado em certas áreas, as quais são objeto de atuação dessas ações de voluntariado como uma maneira de suprir e/ou integralizar esses espaços. De acordo com Herrera Flores (2002), como o sistema de valores hegemônico atualmente é o do neoliberalismo, que privilegia o mercado em detrimento da igualdade social, por certo que as normas jurídicas também encartarão esse viés e serão aplicadas a partir dessa orientação neoliberal - e isso teve severa influência no esmorecimento do estado de bem estar social. Assim é que há sérios entraves a certos grupos e pessoas para as suas buscas de garantias jurídicas para acesso aos bens necessários. Hoje, o poder público assume de forma comedida suas competências, necessitando da atuação de outros atores a fim de manter um mínimo existencial aos vulneráveis.

Nesse ponto, a atuação dos movimentos sociais assume importante papel desde o final do século XX. Se antes tais movimentos eram ligados à categoria sindical, hoje a luta social é mais

\footnotetext{
${ }^{3}$ Em tradução livre: Há uma forte consciência dos fracassos de sua ação institucional e pensam a partir da função social positiva que desempenham, mas também daquelas insuficiências que desejam superar, embora em alguns aspectos não seja fácil.

${ }^{4}$ Em tradução livre: Estando em contato direto com situações de injustiça e disfunções derivadas do sistema, forma-se uma consciência social que leva à articulação de um discurso crítico em relação à ordem instituída e também à denúncia social.
} 
ampla, com diversos eixos de luta: identitários, multiculturais, contra o neoliberalismo etc. (GOHN; BRINGEL, 2012). Nesse último grupo, dos que combatem o capitalismo neoliberal, surgem vertentes, algumas ligadas ao marxismo clássico e outras com uma visão mais contextualizada, na qual o passado serve como memória de formas de resistência às formas de dominação do capital (GOHN; BRINGEL, 2012). Importante ressaltar o caráter político dos movimentos, aqui não se querendo apontar caráter partidário, afinal as pessoas que participam deles estão exercitando a política, mas não fazem parte das elites que lutam pelo poder. Hoje, com a fragmentação das ações coletivas, os movimentos sociais adotam campos multifacetados, incluindo-se a atuação direta junto às comunidades vulneráveis (GOHN; BRINGEL, 2012).

A atuação voluntária, para ser emancipadora, não pode ser a simples ação assistencialista, e sim uma atuação contextualizada, sendo necessário ao agente transformador uma visão global da sociedade. Segundo Selli e Garrafa (2004), a solidariedade crítica deve ser orientadora do serviço voluntário orgânico. A visão crítica diz da capacidade do agente de possuir critérios capazes de visualizar as dimensões social e política presentes na ação solidária. Assim, a solidariedade não se esgota como uma típica relação civil.

A efetivação dos direitos humanos, enquanto processo de luta, pode ser alvo das ações de voluntariado. Herrera Flores (2009) propôs, retomando as ilações destacadas anteriormente, que os direitos humanos devem pressupor que vivemos em um mundo no qual há a necessidade de satisfação de certos bens materiais e imateriais. Todavia, o acesso a eles é hierarquizado, decorrente de um sistema de valores e processos históricos e, por isso, o objetivo das lutas sociais é a vida com dignidade, que generalize o acesso igualitário aos bens materiais e imateriais.

Nem sempre, contudo, os grupos mais vulneráveis estão em condição de obterem êxito em seus pleitos por essa pretendida igualdade de acesso aos bens para uma vida digna. Daí ressai a valia do voluntariado como agente transformador da realidade desses indivíduos, suportando e fomentando os processos de lutas históricas que, para Herrera Flores (2009), são a autêntica versão dos direitos humanos. A retórica de que todos têm direitos porque nasceram humanos, como também mencionado nas linhas iniciais, é ilusória, pois a mera constituição formal de direitos através de atos normativos jurídicos não os constitui concretamente, tampouco é suficiente para impor ao Estado um dever compulsório de pleno atendimento.

Direitos humanos são, pois, a luta pelo acesso aos bens que conforma a dignidade humana, não sendo constituídos por uma existência legal (HERRERA FLORES, 2002). Além, os direitos humanos são uma maneira de expandir a capacidade do indivíduo de atuar no mundo 
(HERRERA FLORES, 2002) e, por conta dessa característica, o voluntariado pode ser uma maneira de integrar os sujeitos a esse papel que lhes convêm, que lhes propicie a escolha de alteração do seu status - ou seja, o processo histórico de luta social, como mencionado.

Assim é que o voluntariado, para ser transformador, precisa estar próximo das pessoas, evitando-se um assistencialismo elitista, que mais reforça os estereótipos dos vulneráveis do que os ajuda. Precisa estar orientado, pois, para a colaboração nas lutas sociais pela vida digna, pelos direitos humanos e para uma cultura por direitos humanos. Para Fernández e López (2007), a proximidade da realidade das ruas e das pessoas nas situações concretas de exclusão são uma grande força de um verdadeiro voluntariado. Hoje nosso modelo social perde essa sinergia com a comunidade, pois se mostra cada vez mais midiático, sendo que a proximidade se torna um valor escasso. Ainda, segundo os autores (2007), a ação voluntária tem uma necessária integração do voluntário com o destinatário da ação e, por conseguinte, uma integração maior com a comunidade, sendo isso uma força importante do voluntariado. Além disso, o exercício de uma solidariedade ativa propicia confiança no destinatário da ação, que estabelece uma relação distinta com o voluntário que com a administração pública ou seus representantes.

Em análise sobre as categorizações de trabalho voluntário, Souza e Medeiros (2012), esboçaram uma hierarquia do trabalho voluntário em cinco níveis: a) altruísta, no qual se verifica um sacrifício por parte do voluntário, sob a perspectiva da consciência de espécie e de questionamento em torno das condições gerais de vida de seres humanos; b) afetivo, apoio direto aos assistidos, com o interesse no resgate da cidadania; c) amigável, no qual se objetiva o bem-estar social sob uma perspectiva amistosa, como se o voluntário estivesse compartilhando algo com alguém; d) ajustado, no qual envolvem ações não centradas em temas cruciais mas, de certa forma, transmite ao voluntário a sensação de estar promovendo a si próprio e a vida do receptor; e) ajuizado, que congrega motivos centrados na sensação de privilégios, status e proteção, estando o voluntário interessado na construção e projeção da autoimagem e promoção pessoal.

A participação voluntária para ser agente de direitos humanos tem que ser altruísta - ou ao menos afetiva, autêntica. Nas palavras de Selli e Garrafa (2006), a participação precisa ser orgânica. Para os autores, o voluntariado orgânico, o qual deriva do conceito de intelectual orgânico formulado por $\mathrm{Gramsci}^{5}$, trabalha uma dimensão ética aplicada à atuação, como

\footnotetext{
${ }^{5}$ Segundo SEMERARO (2006), para Gramsci, os intelectuais são intimamente entrelaçados nas relações sociais, pertencentes a uma classe, a um grupo especial em um modo de produção. Diferenciavam-se dos intelectuais tradicionais, estes ligados a uma formação socioeconômica superada. Assim, o intelectual orgânico é o que elabora
} 
justiça, cidadania, direitos humanos, liberdade, tolerância etc. Tal conceito, segundo os autores, comporta características específicas que o identificam, dentre outras: a) a conduta voluntária é uma ação racional com relação a um valor: a solidariedade crítica; b) a conduta voluntária preenche uma série de requisitos, os quais serão enunciados a seguir; c) é na condição de pessoa que o agente dirige-se aos membros da coletividade; d) é um compromisso personalíssimo que não se liga a qualquer forma de ativismo que busque no voluntariado uma função instrumental; d) não vê em sua criação uma moeda de troca ou forma de barganha psicológica ou religiosa; e) é uma busca da reciprocidade e da alteridade; f) é uma busca pela justiça dos destinatários da conduta voluntária libre de paternalismo ou qualquer outra forma de autoritarismo; g) deve partir de uma postura democrática, na qual vê no outro um igual, bem como de uma postura tolerante, pluralista, buscando a ruptura dos antigos parâmetros imobilizantes.

A ação voluntária para ser emancipadora precisa extirpar-se dos estereótipos de uma simples distribuição de pequenos auxílios aos mais necessitados. Esse tipo de voluntariado, segundo Alcade-Corzo (2018), trabalha com uma visão conservadora da sociedade de consumo, reforçando as preconcepções quanto aos menos favorecidos - descambando para o aprofundamento do abismo social existente. Da mesma forma, a utilização do voluntariado como um instrumento, seja complementar das políticas públicas, seja das próprias entidades sociais, propicia a perda de toda a capacidade transformadora da ação. Sobre a retórica da mudança, segundo o autor, "ésta pasa muchas veces a un segundo plano, contradiciéndose con la práctica que -principalmente - se centra en tareas de asistencia, cuidado, promoción de la autonomía y atención directa a los excluídos”6 (ALCADE-CORZO, 2018, p. 246).

O voluntariado transformador precisa ser, nas palavras de García Roca (2001), um voluntariado maduro, que se caracteriza pela denúncia do encolhimento do Estado, o que só beneficia quem está acima na hierarquia. O voluntariado maduro exige o compromisso ativo do Estado na construção de direitos sociais, e a ação voluntária pode auxiliar na exigência dessa atuação. O caráter instrumental do voluntariado atinge o voluntariado maduro, este não reconhecendo uma função auxiliar da administração. Para o autor, a solidariedade demanda visibilidade nas relações pessoais, isto não se confundindo com promoção pessoal. Trata-se de evitar a opacidade das relações institucionais, as quais debilitam a verdadeira solidariedade que

uma concepção ético-política que habilita, além dos seus ofícios, a exercer diversas funções para assegurar a hegemonia social da classe que representam. Para Gramsci, economia, política cultura e filosofia são partes orgânicas a inseparáveis da mesma realidade.

${ }^{6}$ Em tradução livre: Muitas vezes isso vai para o segundo plano, contrariando a prática que - principalmente centra-se nas tarefas de assistência, cuidado, promoção da autonomia e atenção direta aos excluídos. 
tenta aproximar, que tenta propiciar uma experiência plena de solidariedade realmente enriquecedora, tanto para quem recebe como para quem presta o serviço.

Um voluntariado emancipador precisa apostar em processos que tendam a superar o reducionismo individualista liberal da visão atual dos direitos humanos. Para García Inda (1998, p. 20), "los nuevos movimientos sociales como el voluntariado pueden apostar por processos de aglutinación y politización de los mismos, que tiendan a concentrar esos luchas"7. Ainda, segundo o autor, se trata de passar da conquista de direitos para a construção de direitos, sendo que o voluntariado pode ser uma importante contribuição nesse processo. A tarefa de conquista deve ser centrada em conseguir o reconhecimento do Estado desses direitos, e, uma vez obtido, lutar pela construção e efetivação desses direitos reconhecidos. Os movimentos sociais são peça chave nesse trabalho, sendo atores centrais dos processos e dinâmicas de protestos e luta por mudanças e justiça social no mundo contemporâneo (GOHN; BRINGEL, 2012).

Como pontua Herrera Flores (2009), as instituições e categorias são produtos de ficções criadas culturalmente, passíveis de alteração ao longo do tempo caso seja conveniente e haja interação de forças suficientes para tanto. Os direitos humanos como produto cultural são expressões criadas para reagir ao ambiente em que se vive. $\mathrm{O}$ voluntariado transformador, a partir desse viés, precisa estar atento aos contextos históricos e sociais nos quais se situa, para que atue como agente em prol dos direitos humanos dos indivíduos atingidos por suas ações ${ }^{8}$.

Dessa forma, se faz necessária uma visão contextualizada e crítica dos fenômenos vinculados a uma determinada realidade social, a fim que o voluntariado desenvolvido não seja um fim em si mesmo, e que possa fazer a diferença junto ao destinatário da ação. É importante uma atuação orgânica dos agentes sociais, a fim de que se possa criar uma cultura ativa de direitos humanos na sociedade, a fim de que a luta para a obtenção dos meios necessários para a vida digna seja empreendida com sucesso.

\section{Considerações finais}

No decorrer do presente estudo, foi verificado que é necessária uma visão emancipatória dos Direitos Humanos, entendidos como um processo de lutas pela dignidade. Assim, deve-se

\footnotetext{
${ }^{7}$ Em tradução livre: Novos movimentos sociais como o voluntariado podem apostar em processos de aglutinação e politização dos mesmos, que tendem a concentrar essas lutas.

${ }^{8}$ Herrera Flores (2009, p. 59) destaca, ao desvelar sua teoria para os direitos humanos, que "uma teoria crítica do direito deve se sustentar, então, sobre dois pilares: o reforço das garantias formais reconhecidas juridicamente, mas, igualmente, o empoderamento dos grupos mais desfavorecidos ao lutar por novas formas, mais igualitárias e generalizadoras, de acesso aos bens protegidos pelo direito".
} 
desligar das amarras ideológicas que nos prendem a uma visão eurocentrista e elitizada do problema da concretização dos direitos.

Em um momento de crise do Estado de bem-estar social, em muito causada pelo avanço neoliberal, o qual trata a questão social como um custo a ser cortado, o Estado se afasta do perfil de bem-estar social que permeou sua atuação em boa parte do século XX. Essa ausência de atuação faz florescer na sociedade civil os movimentos questionadores do sistema neoliberal. Se antes essas movimentações se cingiam à luta sindical, a partir do final do século XX a atuação toma novas nuances, mais integradas aos problemas sociais e reconhecendo no outro o papel de concidadãos. Assim, a sociedade civil aumenta seu campo de atuação para suprir a falha de cobertura das ações sociais. Assim, uma rede de organizações civis voluntárias cresce em quantidade e em importância junto aos corpos vulneráveis de nossa sociedade.

Para uma ação social efetiva, que tenha aderência a uma teoria de efetividade pelos direitos humanos enquanto processo de luta social, o voluntariado empreendido não deve ser meramente assistencial, mas sim uma atuação contextualizada com os problemas sociais e políticos que permeiam a situação das comunidades. Uma visão solidária crítica na atuação pode auxiliar em uma emancipação democrática das populações, criando nestas uma cultura ativa de direitos humanos, entendido como o contexto de lutas explicitado.

Essa atuação é denominada como voluntariado orgânico, no qual a participação crítica das pessoas que desenvolvem a atividade voluntária é uma contribuição na construção de condições necessárias ao cumprimento dos compromissos do Estado. O voluntariado cumpre importante papel pedagógico nesse processo, esclarecendo aos setores populares os seus direitos fundamentais e os meios para a concretização.

Além disso, o voluntariado deve ser maduro, este compreendido como aquele que rompe as amarras da instrumentalidade, fugindo à incorporação da atuação como extensão do Estado neoliberal, que cada vez mais se encolhe. Essa atuação deve buscar a aproximação com a sociedade, longe da opacidade propiciada por uma atuação meramente institucional.

Assim, a atividade voluntária emancipadora deve ser acompanhada com comprometimento de um cidadão que sabe seu papel na sociedade civil, como mensageiro dos segmentos que não possuem voz, além de empoderar as populações para que prossigam nas lutas por melhores condições para uma vida digna.

\section{Referências}


ALCALDE-CORZO, Rocío. Voluntariado y Derechos Humanos. Trabajo Social GlobalGlobal Social Work, [S.L.], v. 8, p. 235-253, 30 maio 2018. Editorial de la Universidad de Granada. Disponível em: http://dx.doi.org/10.30827/tsg-gsw.v8i0.6544. Acesso em: 07 mai. 2021.

BRAGATO, Fernanda Frizzo. Para além do discurso eurocêntrico dos direitos humanos: contribuições da descolonialidade. Novos Estudos Jurídicos, v. 19, n. 1, p. 201-230, abr. 2014. DOI: http://dx.doi.org/10.14210/nej.v19n1.p201- 230. Disponível em: https://siaiap32.univali.br/seer/index.php/nej/article/view/5548. Acesso em: 17 abr. 2021.

CADEMARTORI, Luiz Henrique Urquhart; GRUBBA, Leilane Serratine. O embasamento dos direitos humanos e sua relação com os direitos fundamentais a partir do diálogo garantista com a teoria da reinvenção dos direitos humanos. Rev. direito GV. São Paulo, v. 8, n. 2, p. 703-724, Dec. 2012. Disponível em:

http://www.scielo.br/scielo.php?script=sci_arttext\&pid=S1808-

$24322012000200013 \& \operatorname{lng}=\mathrm{en} \& \mathrm{nrm}=\mathrm{iso}$. Acesso em 06 maio

2021. https://doi.org/10.1590/S1808-24322012000200013.

CARVALHO, Virgínia Donizete de; SOUZA, Washington José de. Pobres no ter, ricos não ser: trabalho voluntário e motivação na Pastoral da Criança. Rev. adm. contemp., Curitiba, v. 11, n. 2, p. 113-134, jun. 2007. Disponível em:

http://www.scielo.br/scielo.php?script=sci_arttext\&pid=S1415-

65552007000200007\&lng=en\&nrm=iso. Acesso em 06 abr. 2021.

https://doi.org/10.1590/S1415-65552007000200007.

CERVI, Jacson Roberto. As intersecções jurídicas entre o público e o privado e o comunitarismo responsivo sob a óptica constitucional. In: REIS, Jorge Renato dos; CERQUEIRA, Kátia Leitão (org). Intersecções jurídicas entre o público e o privado. Santa Cruz do Sul: IPR, 2013. p. 147-204.

CHAUÍ, Marilena. A Ideologia da Competência. São Paulo: Editora Fundação Perseu Abramo, 2014.

COLAÇO, Thais Luzia e DAMÁZIO, Eloise da Silveira Petter. Um diálogo entre o Pensamento Descolonial e a Antropologia Jurídica: elementos para o resgate dos saberes jurídicos subalternizados. Sequência: Publicação dos Cursos de Pós-Graduação em Direito da UFSC. Florianópolis, v. 31, n. 61, p. 85-110, 2010. Disponível em: https://periodicos.ufsc.br/index.php/sequencia/article/view/2177-7055.2010v31n61p85. Acesso em: 06 mai. 2021. Doi:10.5007/2177-7055.2010v31n61p85.

COSTA, Marcelo Marchesini da. Assessing government-nonprofit collaborations and density of nonprofit organizations in Brazil. Rev. Adm. Pública, Rio de Janeiro, v. 51, n. 3, p. 330347, jun. 2017. Disponível em:

http://www.scielo.br/scielo.php?script=sci_arttext\&pid=S0034-

$76122017000300330 \& \operatorname{lng}=$ en\&nrm=iso. Acesso em 03

mai. 2021. https://doi.org/10.1590/0034-7612155003.

ETZIONI, Amitai. A terceira via para a boa sociedade: seguido dos manifestos comunitaristas: Plataforma comunitarista responsiva e manifesto pela diversidade na unidade. 
Tradução: João Pedro Schmidt. Santa Cruz do Sul: EDUNISC, 2019. E-book. Disponível em: https://repositorio.unisc.br/jspui/bitstream/11624/2721/1/A\%20terceira\%20via\%20para\%20a $\% 20$ boa\%20sociedade.pdf. Acesso em: 04 set. 2020.

FAGUNDES, Helenara Silveira. O Voluntariado a Solidariedade e as Políticas Sociais.

Textos \& Contextos (Porto Alegre), v. 5, n. 2, p. 1-19, 20 dez. 2006. Disponível em: https://revistaseletronicas.pucrs.br/ojs/index.php/fass/article/view/1029. Acesso em: 06 mai. 2021.

FERNÁNDEZ, Fernando Vidal e LÓPEZ, Rosalía Mota. Voluntariado cívico: la percepción de las organizaciones de voluntariado sobre su desarrollo. Miscelánea Comillas: Revista de Ciências Humanas y Sociales. [S.L], v. 65, n. 127, p. 605-662. Jul-dez. 2007. Disponível em: https://revistas.comillas.edu/index.php/miscelaneacomillas/article/view/7328. Acesso em: 08 mai. 2021.

FERRAJOLI, Luigi. Direito e Razão: teoria do garantismo penal. Tradução de Ana Paula Zomer, Fauzi Hassan Choukr, Juarez Tavares, Luiz Flávio Gomes. São Paulo: Editora Revista dos Tribunais, 2002.

FIGUEIRÓ, M. L. S.; SOUZA, F. E. P.; REBELO, N. G. Organizações Voluntárias: informação para a conquista da cidadania. Encontros Bibli: revista eletrônica de biblioteconomia e ciência da informação, [S. 1.], v. 6, n. 11, p. 52-72, 2001. DOI: 10.5007/1518-2924.2001v6n11p52. Disponível em: https://periodicos.ufsc.br/index.php/eb/article/view/1518-2924.2001v6n11p52. Acesso em: 16 abr. 2021.

GARCÍA INDA, A. El voluntariado como fundamento de los derechos humanos. Cuadernos de Trabajo Social, [S.L], n. 11, p. 15-29, jan. 1998. Disponível em:

https://revistas.ucm.es/index.php/CUTS/article/view/CUTS9898110015A. Acesso em 08 mai. 2021.

GARCÍA ROCA, Joaquin. El voluntariado en la sociedad de Bienestar. Documentación Social. [S.L], n. 122, 2001. Disponível em:

http://participacionsocial.aytosalamanca.es/es/agenciadevoluntariado/docs/EL_VOLUNTARI ADO_EN_LA_SOCIEDAD_DE_BIENESTAR.PDF. Acesso em: 10 maio 2021.

GOHN, Maria da Glória; BRINGEL, Breno M. Movimentos sociais na era global. Rio de Janeiro: Vozes, 2012. E-book.

GOHN, Maria da Gloria. Sociedade Civil no Brasil: movimentos sociais e ONGs. Revista Meta: Avaliação, [S.1.], v. 5, n. 14, p. 238-253, sep. 2013. ISSN 2175-2753. Disponível em: https://revistas.cesgranrio.org.br/index.php/metaavaliacao/article/view/145. Acesso em: 03 mai. 2021. doi:http://dx.doi.org/10.22347/2175-2753v5i14.145.

GOHN, Maria da Gloria. Sociedade Civil no Brasil: movimentos sociais e ONGs. Revista Meta: Avaliação, [S.1.], v. 5, n. 14, p. 238-253, sep. 2013. ISSN 2175-2753. Disponível em: https://revistas.cesgranrio.org.br/index.php/metaavaliacao/article/view/145. Acesso em: 06 mai. 2021. doi:http://dx.doi.org/10.22347/2175-2753v5i14.145. 
GRUBBA, Leilane Serratine. O ENSINO DOS DIREITOS HUMANOS: A POESIA COMO FORMA DE LIBERTAÇÃO DO DESEJO. Revista Direitos Culturais, [S.1.], v. 5, n. 9, p. 99-108, mai. 2011. ISSN 2177-1499. Disponível em:

http://srvapp2s.santoangelo.uri.br/seer/index.php/direitosculturais/article/view/485. Acesso em: 06 mai. 2021. doi:http://dx.doi.org/10.20912/rdc.v5i9.485.

GRUBBA, Leilane Serratine; CADEMARTORI, Luiz Henrique Urquhart. DIREITOS HUMANOS E DIREITOS FUNDAMENTAIS: CONVERGÊNCIAS ENTRE JOAQUÍN HERRERA FLORES E LUIGI FERRAJOLI. Espaço Jurídico Journal of Law [EJJL], [S. 1.], v. 13, n. 1, p. 157-178, 2012. Disponível em: https://portalperiodicos.unoesc.edu.br/espacojuridico/article/view/1445. Acesso em: 6 maio. 2021.

HERRERA FLORES, Joaquín. A (re)invenção dos direitos humanos. Florianópolis: Fundação Boiteux, 2009. 232 p. Tradução: Carlos Roberto Diogo Garcia; Antônio Henrique Graciano Suxberger; Jefferson Aparecido Dias.

HERRERA FLORES, Joaquin. Direitos humanos, interculturalidade e racionalidade de resistência. Sequência: Revista do Curso de Pós-Graduação em Direito da UFSC. Florianópolis, v. 44, p. 9-29. Disponível em: https://periodicos.ufsc.br/index.php/sequencia/article/view/15330. Acesso em: 06 mai. 2021.

MORIN, Edgar. É hora de mudarmos de via: as lições do coronavírus. Tradução de Ivone C. Benedetti. Rio de Janeiro: Bertrand Brasil, 2020. E-book.

MIGNOLO, Walter D. COLONIALIDADE: o lado mais escuro da modernidade. Revista Brasileira de Ciências Sociais, v. 32, n. 94, p. 1-18, 2017. DOI: http://dx.doi.org/10.17666/329402/2017. Disponível em: https://www.scielo.br/scielo.php?pid=S010269092017000200507\&script=sci_abstract\&tlng=pt. Acesso em: 18 abr. 2021.

PERLATTO, Fernando. Esferas públicas no Brasil: teoria social, públicos subalternos e democracia. Curitiba: Appris, 2018.

PIKETTY, Thomas. Capital e ideologia. Tradução de Dorothée de Bruchard, Maria de Fátima O. do Couto. Rio de Janeiro: Intrínseca, 2020. E-book.

PIKETTY, Thomas. O Capital no século XXI. Tradução de Monica Baumgarten de Bolle. Rio de Janeiro: Intrínseca, 2014. E-book.

SCHMIDT, João Pedro. Condicionantes e diretrizes de políticas públicas: um enfoque comunitarista da transformação social. Revista Brasileira de Políticas Públicas, Brasília, v. 6, n. 3, p. 51-72. DOI: 10.5102/rbpp.v6i3.4400. Disponível em: https://www.publicacoesacademicas.uniceub.br/RBPP/article/download/4400/pdf. Acesso em: 04 set. 2020.

SASSEN, Saskia. Sociologia da globalização. Porto Alegre: Artmed, 2010. 
SELLI, Lucilda; GARRAFA, Volnei. Bioética, solidariedade crítica e voluntariado orgânico. Revista de Saúde Pública, [S.L.], v. 39, n. 3, p. 473-478, jun. 2005. Disponível em: http://dx.doi.org/10.1590/s0034-89102005000300020. Acesso em: 07 mai. 2021.

SELLI, Lucilda; GARRAFA, Volnei. Solidariedade crítica e voluntariado orgânico: outra possibilidade de intervenção societária. História, Ciências, Saúde-Manguinhos, [S.L.], v. 13, n. 2, p. 239-251, jun. 2006. Disponível em: http://dx.doi.org/10.1590/s010459702006000200003. Acesso em: 07 mai. 2021.

SEMERARO, Giovanni. Intelectuais "orgânicos" em tempos de pós-modernidade. Cadernos Cedes, [S.L.], v. 26, n. 70, p. 373-391, dez. 2006. Disponível em:

http://dx.doi.org/10.1590/s0101-32622006000300006. Acesso em: 07 mai. 2021.

SILVA, Enio Waldir da. Estado, sociedade civil e cidadania no Brasil: Bases para uma cultura de direitos humanos. Ijuí: Editora Unijuí, 2014

SOUZA, Jessé. A modernização seletiva: uma reinterpretação do dilema brasileiro. Brasília: Editora Universidade de Brasília, 2000.

SOUZA, Jessé. Ralé Brasileira: quem é e como vive. Belo Horizonte: Editora UFMG, 2009.

SOUZA, Washigton José de; MEDEIROS, Jássio Pereira de. Trabalho voluntário: motivos para sua realização. Revista de Ciências da Administração, [S.L.], p. 93-102, 17 jul. 2012. Universidade Federal de Santa Catarina (UFSC). Disponível em: http://dx.doi.org/10.5007/2175-8077.2012v14n33p93. Acesso em 08 mai. 